\title{
A Sensitivity Analysis Study of the SPITFIRE Fire Model
}

\author{
J L Gómez-Dans ${ }^{\mathrm{a}, \mathrm{b}, *}$, A Spessa ${ }^{\mathrm{c}}$, M Wooster ${ }^{\mathrm{a}}$, P Lewis $^{\mathrm{b}}$ \\ ${ }^{a}$ Department of Geography, King's College London, Strand, London, WC2R 2LS, United \\ Kingdom \\ ${ }^{b}$ Department of Geography, University College London, Pearson Building, Gower Street, WC1E \\ 6BT, United Kingdom \\ ${ }^{c}$ Department of Meteorology, University of Reading, Earley Gate, PO Box 243, Reading, RG6 \\ 6BB, United Kingdom
}

\begin{abstract}
Keywords: fire modelling, sensitivity analysis, DGVM, vegetation modelling
\end{abstract}

\section{Contents}

2 Materials 4

2.1 Model description . . . . . . . . . . . . . . . . . . . 4

2.2 Sensitivity analysis . . . . . . . . . . . . . . 6

2.2.1 The Morris screening method . . . . . . . . . . . . . 6

2.2 .2 The Sobol' SA procedure . . . . . . . . . . . . . 7

2.2.3 Assessing the robustness of the SA results . . . . . . . . 8

2.3 Fire model drivers . . . . . . . . . . . . . . . . . . . . . . . . . 9

2.4 Site descriptions . . . . . . . . . . . . . . . . . . . . . . . . . . 9

2.4 .1 Boreal . . . . . . . . . . . . . . . . . . . . . 10

2.4 .2 Savannas . . . . . . . . . . . . . . . . . . . 10

2.4 .3 Temperate . . . . . . . . . . . . . . . 10

2.4 .4 Tropical . . . . . . . . . . . . . . . . . . 11

3 Results 11

3.1 Individual model components . . . . . . . . . . . . . . . . . . . . . 11

3.1 .1 Potential ignitions . . . . . . . . . . . . . . . . . 11

3.1 .2 Fuel moisture dynamics . . . . . . . . . . . . . . . . . 12

3.1 .3 Rate of spread . . . . . . . . . . . . . . . . . . . 12

3.2 Sensitivity analysis per biome . . . . . . . . . . . . . . 13

3.2.1 Boreal forests . . . . . . . . . . . . . . . . . . . . 13

3.2 .2 Savannahs . . . . . . . . . . . . . . . . . . . . . . 14

3.2 .3 Temperate regions . . . . . . . . . . . . . . . . . . 15

3.2 .4 Tropical rainforest $\ldots \ldots \ldots \ldots \ldots$

4 Discussion $\quad 16$

5 Conclusions 18

\footnotetext{
* Corresponding author

Email addresses: j.gomez-dans@geog.ucl.ac.uk (J L Gómez-Dans), a.spessa@reading.ac.uk (A Spessa), m.wooster@kcl.ac.uk (M Wooster), plewis@geog.ucl.ac.uk (P Lewis)
} 


\section{Introduction}

Fire is the main source of disturbance to vegetation, present in all biomes and continents (Van der Werf et al., 2006). As such, the description of fire and its effects on vegetation is an important part of quantifying fluxes from the land sink to the atmosphere (Giglio et al., 2005; Randerson et al., 2005). Fire is a complex phenomenon, regulated by climate, vegetation and human activity, in turn impacting vegetation productivity, succession and (Bergeron et al., 2004; Goldammer and Furyaev, 1996; Cochrane, 2003; Whelan, 1995). Fire controls are different in different ecosystems: in the boreal region, temperature controls fire occurrence (Flannigan et al., 2005), and limits the length of the fire season. In semi-arid, savannas and mediterranean ecosystems, typically exhibiting seasonal or inter-annual rainfall patterns, it is fuel availability that controls fires (Randerson et al., 2005; Archibald et al., 2009). In the tropics, precipitation controls fires, either by depressing its occurrence in moist rainforests (Cochrane, 2003), or by promoting biomass accumulation during the wet season in tropical savannas. The variability of burned area in these ecosystems appears related to El Niño -Southern-Oscillation occurrence (Harris et al., 2008; Randerson et al., 2005; Kitzberger et al., 2001; van der Werf et al., 2008).

Analyses of fire acvtivity patterns and the factors driving these patterns, are predominantly based on Earth Observation (EO) data [REFS!!]. High quality EO data has only emerged within the last decade or so, and hence cannot be used to assess fire activity that occurs over multidecadal timescales. Also, EO data cannot be used to predict fire activity and its effects in the future. Models that make predictions outside the contemporary satellite data record are clearly necessary. We stress the necessity of these models being throughly validated as well as providing estimates of uncertainties in modelled magnitudes.

Prognostic fire models, embedded in dynamic global vegetation models (DGVMs) can in principle simulate the effects of changes in climate and vegetation dynamics as a bidirectional feedback with the embedded fire model. This capability allows us to investigate how fire and fire-related emissions might change with changing climate conditions and vegetation dynamics. There have been several attempts to simulate fire as an interactive component of DVMs (Lenihan et al., 1998; Thonicke et al., 2001; Venevsky et al., 2002; Arora and Boer, 2005; Lehsten et al., 2008).

Such models are primarily designed to incorporate the role of fire as a disturbance factor for vegetation dyanmcis and to account for corresponding fluxes in the global carbon cycle. Trace gas and aerosol emisssions can also be derived within these models via the use of emissions factors, that map combusted biomass into amounts of emitted species (Andreae and Merlet, 2001).

The SPITFIRE (SPread of and InTensity of FIRE) fire model has been designed to overcome some limitations of previous fire models set within DGVM frameworks, while being flexible enough to allow both global and regional simulations using only minimal input data requirements (Thonicke et al., 2010). SPITFIRE was originally developed as an embedded module within the LPJ DGVM framework and is a 
successor to the RegFIRM fire model (Venevsky et al., 2002). RegFIRM explicitly simulates processes of climatic fire danger and lightning and human caused ignitions. SPITFIRE builds on this treatment with a more complete representation of ignitions and fire spread (if conditions are conducent to fires spreading), and comprises new process-based submodels of fire intensity and the risk of vegetation dying from either crown scorch or cambial death (the two most important causes of post-fire mortality), as well as emissions of trace gases and aerosols from biomass burning. The basic premise behind SPITFIRE is that one needs three precursors to fire occurrence: an ignition source (lightning or human-related), a sufficient amount of fuel, and a fuel bed that is dry enough (Pyne et al., 1996). In summary, the model tries to account for

- ignition sources (both human and lightning strikes),

- fuel types,

- fuel susceptibility to fire through modelling of fuel moisture dynamics,

- fire spread dynamics,

- crown scorching versus ground fires,

- modelling of fire-induced plant mortality.

This ambitious choice of processes adds a considerable degree of complexity to the model. This complexity manifests itself in a large set of parameters that control the different sub-models. However, there is a paucity of ground data in the literature with which to parametrise the model, with the added complication that these studies are usually biome, location or scale dependent. Due to the strong non-linearities and strong coupling between different sub-models, effects of individual parameters in the typical model outputs considered as model diagnostic (burned area, number of fires, emissions, etc.) are often difficult to isolate. The implication is that it is difficult to see what parameters can be constrained by what diagnostic observations. For global applications, users have to rely on the availability of a handful of imperfect datasets describing burned area or combusted biomass, typically derived from EO platforms, and perform an inverse modelling exercise [REF], in which the model parameters are treated like variables and tweaked so as to fit the observations within their margin of error. The limitation of a few noisy products available for inverse modelling studies limits the number of parameters that can be effectively constrained. In some circumstances, parameters may need to lose part of its physical meaning and become "effective". It is thus important to concentrate on parameters that can be effectively constrained by the available observations, or in other words, on a reduced set of key parameters that demonstrably display the strongest contribution to model output in comparison to acalibration standard.

A crucial step towards defining a set of key parameters for any model is to carry out a comprehensive sensitivity analysis (SA) exercise, where the impact of model parameters in model output is assessed and parameters are ranked by importance 
(Saltelli et al., 2004). This paper performs a comprehensiveSA of the SPITFIRE model, focussing on parameters influencing the simulation of burnt area and a a sample of sites covering a range of biomes. We seek to identify which parameters and parameter combinations in the fire model, when perturbed cause the biggest changes to burnt area. We use an off-line version of SPITFIRE, in which climate and biomass inputs to the fire model are prescribed by daily meteorology and monthly biomass data based on CASA/GFED (Van der Werf et al., 2006) simulations. Vegetation inputs were prescribed because the focus is in the behaviour of the fire model, and the feedback between fire and vegetation only complicates this endeavour. The results of the SA work are used to assess the importance of different parameters in the fire model across different biomes, and what this means for improved fire prediction.

We propose to carry out such work in this paper, using an off-line version of the SPITFIRE model. This is done by feeding the model meteorological and vegetation inputs and then running the SPITFIRE model for each day in the year. The vegetation is calculated using the GFED/CASA model, a vegetation model that is driven by monthly meteorological inputs and EO data. Typical climatic patterns, including inter-annual variability, as well as variation of fuel loads and types, need to be taken into account to assess sensitivity of the fire model to its drivers. Further, we hypothesise that for different biomes, different sets of parameters are likely to be of importance.

\section{Materials}

\subsection{Model description}

[Figure 1 about here.]

The SPITFIRE fire model is described in depth in (Thonicke et al., 2010), but this Section provides a brief description of how the model calculates burned area. A diagram is shown in Fig. 1. SPITFIRE is fed fuels in terms of 1-hr, 10-hr, 100-hr and 10000-hr fuel loads per plant functional type (PFT) from a dynamic global vegetation model (DGVM). Other inputs relate to daily series of phenology, soil moisture, wind speed, precipitation, minimum, maximum and mean daily temperatures. Above and below ground litter pools are also required. SPITFIRE calculates the number of potential ignitions due to human activity (function of population density and observation-based estimates of the spatial distribution of human-caused ignitions across model cells) and lightning strikes (from an observed lightning climatology dataset). The Nesterov Index (NI), defined as

$$
N I=\sum T_{\max }(d) \cdot\left(T_{\max }(d)-T_{\text {dew }}(d)\right),
$$

where $T_{\max }$ and $T_{\text {dew }}$ are the daily maximum and dew-point temperature. In Eq. 1, teh summation is a accumulation that is reset when precipitation for a given day is greater than $3 \mathrm{~mm}$. The Nesterov Index is the is used as a basis to calculate the 
moisture content of the different fuel pools:

$$
\omega_{o}=\exp \left\{-\left[\sum_{i=1}^{3} \alpha_{i} \cdot \frac{w_{o i}}{w_{o}}\right] \cdot N I\right\},
$$

where $w_{o i}$ is the amount of fuel in the 1-, 10- and 100-hr fuel classes, $w_{o}$ is the total fuel, and $\alpha_{i}$ is a constant that controls the scaling of $N I$ weighted by the relative abundance of each fuel class. For each fuel class, $\alpha$ is defined as the value of $\alpha_{1 h r}$ divided by the ratio of surface-area to volume value of the 1-hr fuel class to the fuel class in question:

$$
\alpha_{i}=\alpha_{1 h r} \cdot \frac{\sigma_{i}}{\sigma_{1 h r}} .
$$

An additional and important use of $N I$ is in defining a (normalised) fire danger index (FDI), that is zero if $\omega_{0}$ is higher than the moisture of extinction, $m_{e}$, or if no fuel is available. Otherwise, it is calculated as $1-\frac{\omega_{o}}{m_{e}}$, explicitly

$$
F D I=\max \left\{0,\left[1-\frac{1}{m_{e}} \cdot \exp \left\{-\left[\sum_{i=1}^{3} \alpha_{i} \cdot \frac{w_{o i}}{w_{o}}\right] \cdot N I\right\}\right]\right\} .
$$

The fuel types and loads present in the simulation unit are used to specify a number of variables related to fuel structure. Combined with the moisture content and environmental variables, Rothermel's fire spread equations (Rothermel, 1972) are used to calculate rate of spread $(R o S)$, the speed at which the fire front advances. This quantity is given by

$$
R O S=\frac{I_{R} \cdot \xi\left(1+\Phi_{w}\right)}{\rho \cdot \epsilon \cdot Q_{i g}}
$$

In Eq. $5, I_{R}$ is the reaction intensity (the energy release per unit area of the fire front), $\xi$ is the propagting flux ration (the proportion of the reaction intensity that is used to heat up adjacent fuel particles to igntion), and $\Phi_{w}$ is a scalar that accounts for the effect of wind in increasing the value of $\xi$. The denominator is made up of the product of the fuel bulk density, $\rho$, assigned per PFT and weighted by fuel class. $\epsilon$ is the effective heating number, and expresses the proportion of a fuel particle that is heated to ignition temperature at the time flaming combustion starts. $Q_{i g}$ is the heat of pre-ignition, or the amount of heat required to ignite a mass of fuel. Clearly, the numerator of Eq. 5 accounts for fire spread, while the denominator can be seen as a dampening of spread due to fuel geometry, moisture content and composition of the fuel. Due to the need of using daily meteorological drivers, this estimate of $R o S$ is necessarily an approximation to the steady state, and it is also assumed identical for all fires spreading in the region (usually defined as a gridcell with constant climatic drivers. Typical sizes range from tenths to one or two degrees). The area burned by this 'average fire' is calculated assuming fires are elliptical, with the product of $R o S$ and fire duration (calculated as a function of a maximum fire duration and the $F D I$ ) determining the size major axis of the ellipse, and the length-to-breadth ratio $L B$ (a function of wind speed, and calculated as per (Canadian Forestry Service, 1992)) determining the minor axis. This 'average fire 
size' is multiplied by the number of potential ignitions to obtain realised ignitions.

The intensity of the fire at the flaming front, FI is calculated as per (Byram and Davis, 1959):

$$
F I=H \cdot R o S \cdot W_{c},
$$

where $H$ is the heat content of the fuel, $R o S$ is the rate of spread, and $W_{c}$ is the total combusted fuel in the 1-hr, 10-hr and 100-hr fuel classes. In turn, combusted fuel is a function of fuel moisture, and is calculated using the empirical relationships based on (Peterson and Ryan, 1986). FI is used as a condition to decide whether realised fires spread: fires will only spread if $F I \geq 50 \mathrm{kWm}^{-1}$ (after Pyne et al. (1996)). $I_{\text {surface }}$ is used, in addition to calculate residence time (a function of Rothermel's reaction intensity) and some PFT-specific parameters, to calculate the impact of fire on vegetation, as well as other fire properties (flame height, crown scorching, ground fires, ...).

\subsection{Sensitivity analysis}

Sensitivity analysis (SA) aims to provide an assessment of the influence of a parameter or factors on model output (Saltelli et al., 2004). In general, the influence of parameters in the output is examined by sweeping the value of these parameters over their range of uncertainty, running the model forward, and examining the output. Typical approaches to analysing the output include analysis of variance or regression-based methods (Campolongo and Saltelli, 1997; Archer et al., 1997). The former require numerous runs, and result in an computationally intractable problem. The latter are not ideally suited to complex non-linear models as SPITFIRE. A proxy for the variance-based methods is the screening method of Morris (Morris, 1991; Campolongo et al., 2007), which requires a relatively modest number of model executions to rank factors. The Morris technique has been successfully applied to assess the sensitivity of crop models (Confalonieri et al., 2009, 2010), and a snow cover dynamics model (Thorsen et al., 2010).

In this study, we use the Morris technique for complete model runs, as using a variance method would result in an unmanageable computational cost. For examining individual sub-processes or modules in SPITFIRE, we revert to the variancebased method (since modules contain far fewer parameters than the whole model). The results of the Morris method are found to be comparable to the variance methods in (Confalonieri et al., 2010) and (Campolongo and Saltelli, 1997).

\subsubsection{The Morris screening method}

The Morris screening method is based on the calculation of the so-called 'elementary effects' of each model input factor. The elementary effect is defined as

$$
R_{i}\left(x_{i}, \ldots, x_{N}, \Delta\right)=\frac{M\left(x_{1}, \ldots, x_{i-1}, x_{i}+\Delta, \ldots, x_{N}\right)-M\left(x_{1}, \ldots, x_{N}\right)}{\Delta} .
$$

In Eq. 7, the model output is $M(\underline{\mathrm{x}})$, where $\underline{\mathrm{x}}$ is the $N$-dimensional input vector of model parameters. $\Delta$ is a value related to a discretisation of parameter space into $p$ levels, and is a value between $1 /(p-1)$ and $1-1 /(p-1)$. 
The Morris method calculates the elementary effects of each parameter by sampling random trajectories over the (discretised) parameter space, where each point in a trajectory differs from the previous one in $\pm \Delta$ for only one factor, the rest being kept identical (this is called "one-at-a-time" sampling). Once parameter space has been traversed by the random trajectories and elementary effects for each factor have been calculated, the mean $\mu$ and standard deviation, $\sigma$ are calculated. $\mu$ is related to the influence of each parameter in the output, whereas $\sigma$ accounts for the combined effect of the parameter in question with other parameters, the so-called higher order effects. In (Campolongo et al., 2007), the use of the absolute value of $\mu$, termed $\mu^{*}$ is recommended, as it avoids ambiguity when ranking parameters. A further enhancement is in the way trajectories along parameter space are calculated. (Campolongo et al., 2007) also introduces a way of generating trajectories that maximise parameter space filling.

To illustrate the analysis procedure consider Fig. 2, depicting some hypothetical results of a Morris analysis applied to a model with 5 parameters or factors: $A, B$, $C, D$ and $E$. Parameter $A$ is characterised by a high value of $\mu^{*}$ and a low value of $\sigma$, suggesting that this parameter has a strong direct effect on the output, but does not interact very much with other parameters. Parameters $B$ and $C$ have a similar effect on the output, but the higher $\sigma$ values indicate that the indirect or higher order effects are much larger. $D$ has a small effect on the output, but is strongly coupled with other parameters, while the effect of $E$ is negligible. This example would suggest that $A, B$ and $C$ have an important effect on the output (high values of $\mu^{*}$ ), whereas $D$ and $E$ have only a very marginal effect. Additionally, $B$ and $C$ also show important higher order interactions or indirect effects.

[Figure 2 about here.]

\subsubsection{The Sobol' SA procedure}

The Sobol' method has much in common with ANOVA methodologies (Helton et al., 2006). It aims to partition the total variance of the model into a weighted summation of the individual effects of each factor:

$$
V(y)=\sum_{i=1}^{N} D_{i}+\sum_{i \leq j<\leq N}^{N} D_{i, j}+\ldots+\sum_{i \leq \ldots N}^{N} D_{i, \ldots, N},
$$

where $D_{i}$ is the first order (direct) effect for each factor $x_{i}$ and $D_{i, j}$. is the effect of the interaction between parameters $x_{i}$. Two indices are defined to account for first and higher order sensitivities:

$$
\begin{aligned}
S_{i} & =\frac{D_{i}}{V(y)} \\
S_{T i} & =\frac{V(y)-D_{\sim i}}{V(y)}
\end{aligned}
$$

In Eq. 10, $D_{\sim i}$ is the sum of all variance terms that do not include term $i . S_{i}$ is then the direct impact of factor $i$ on the model output, the first order effect. 
$S_{T i}$ is the combined effect, or higher order effect of the factor $i$ on the output, the term that quantifies the effect of the interaction between parameter $i$ and the other parameters have on the output. Both of these parameters are bounded between zero and one, with factors characterised by values close to unity having an important effect on the output.

As pointed at the beginning of this Section, variance-based decompositions are extremely useful, but computationally costly. The often-used Sobol' method requires $n S \cdot(2 N+2)$ model evaluations, where $n S$ is the number of samples required to estimate the variance. In Saltelli (2002), an extension that calculates the Sobol' indices for both first-order and total indices at the same time (altogether $2 \mathrm{~N}$ indices), at a total cost of $(N+2) \cdot n S$ model evaluations.

\subsubsection{Assessing the robustness of the $S A$ results}

We chose sites that are representative of the range of biomes affected by fire. In order to explore the uncertainty in other factors not directly related to the fire model, such as inter-annual weather variability, the effect of uncertainty of fuel load estimates, and of demographic parameters affecting human-induced ignitions, replicates of the SA exercise were carried out for each site. These replicates comprise a selection of grid cells around a central site gridcell, that aim to capture variability at the site. Since the SA results are different for each replicate, we investigated the consistency of the results. As in Confalonieri et al. (2009), we choose to use the top down concordance coefficient (TDCC) (Helton et al., 2006), a way of estimating the concordance of the rank ordering of factors in each replicate. The TDCC enhances the contribution of important (highly ranked) parameters, while depressing the effect of irrelevant parameters. Its calculation is straightforward: start by defining $S M_{i j}$, the sensitivity measure of parameter $i$, with $j=1, \ldots, n_{R}$ being the replicate number. $r\left(S M_{i j}\right)$ being the rank order associated with parameter $i$, replicate $j$ (1 for the most important parameter, 2 for the second most important, etc.) Next, calculate the Savage scores as

$$
s s\left(S M_{i j}\right)=\sum_{i=r\left(S M_{i j}\right)}^{N} i^{-1} .
$$

The Savage scores are then used to calculate the TDCC (Helton et al., 2006) as

$$
T D C C=\frac{\sum_{i=1}^{N}\left[\sum_{j=1}^{n_{R}} s s\left(S M_{i j}\right)\right]^{2}-n_{R}^{2} \cdot N}{n_{R}^{2} \cdot\left[N-\sum_{i=1}^{N} i^{-1}\right]} .
$$

The TDCC provides an indication of how similar the rank ordering is between different replicates, and gives an idea of the consistency of the sensitivity analysis for a given biome. High values (close to unity) imply that the results are similar, whereas low values indicate that the results are heterogeneous. Note that the latter situation is not necessarily an indication of poor SA performance, as it can arise due to adjcent grid cells being different in terms of demography, climate, fire history, etc. 


\subsection{Fire model drivers}

A number of drivers are required to run SPITFIRE. These are:

1. daily meteorological data (precipitation, dew point, wind speed, minimum, maximum and mean temperatures) and monthly lightning climatology,

2. phenology,

3. top level soil moisture,

4. PFTs present in the grid cell (as well as projected fractional coverage),

5. fuel loads per PFT and fuel class,

6. population density.

The daily meteorological drivers and top layer soil moisture were obtained from the NCEP Reanalysis dataset (Kalnay et al., 1996), and interpolated to 0.5 degrees. The lightning flash monthly climatology is derived from gridded satellite lightning data produced by the NASA LIS/OTD Science Team (Principal Investigator, Dr. Hugh J. Christian, NASA / Marshall Space Flight Center). The PFTs present in each grid cell were derived from the MODIS land cover product (MCD12Q1). Demographic information is derived from a resampled version of the HYDE3 dataset (Goldewijk, 2005). Phenology is only relevant to grasses in SPITFIRE, so it was derived from a scaled trajectory of the monthly MODIS NDVI fitted with a spline polynomial to obtain a daily phenology estimate in the range $[0,1]$.

Fuel loads were simulated with CASA model (Potter et al., 1993; van der Werf et al., 2004; Van der Werf et al., 2003; van der Werf et al., 2010) driven by MODIS monthly NDVI data from 2000 to 2005. Monthly NCEP Reanalysis data were used as inputs for CASA.Burned area data from the GFED dataset were used (Giglio et al., 2010), but for the purpose of this work, monthly fuel loads were calculated without fire disturbance. The model output with observed fire disturbance is used as the starting state for each annual run. The maximum fuel load per year was fed into SPITFIRE. The different litter pools in CASA were associated with different fuel classes, and divided among all the present PFTs weighted by percentage area covered. The mapping from CASA/GFED pools to SPITFIRE fuel classes was as follows: The 1-hr fuel class comprised the tree and grass leaf mass, as well as the grass fine litter contribution. The 10-hr fuel class was made up of fine tree litter. The 100-hr class had the tree coarse debris pool and the 1000-hr class included the tree trunks.

\subsection{Site descriptions}

Fire is a function of ignitions, climate and vegetation, as well as having a conditioning feedback on them (Pyne et al., 1996). Some of these factors can be broadly studied at the biome level (for example, savannas tend to be dominated by grasses while tropical rainforests are dominated by trees), but nonetheless very important to consider how the fire model behaves for the same biome under different weather forcings, or by exploring the effect of heterogeneous landcover or demographics. For example, consider a boreal site where one year is characterised by drought, 
and hence high fire activity, which results in a removal of most of the vegetation. Surrounding sites escape fires during this year even though they possess a sufficient amount of fuel either because of insufficient ignitions and/or the drought was localised in its effect. In subsequent drought years we would expect the site in question to experience little fire activity because most of its vegetation has been removed and vegetation regrowth in high latitudes is comparativeky low. However, this will not apply to the adjacent sites, which may well burn if a confluence of drought conditions and ignitions occur in the future. This example illustrates the importance of having replicate sites to take into account within-biome variability.

Several sites were chosen to be representative of the boreal, savanna, temperate and tropical regions. For each site, a central grid cell was chosen. A range of 25 cells are chosen randomly within a radius of 2 degrees around the central grid cell. In the following sections, we describe the sites grouped by biome.

[Table 1 about here.]

[Figure 3 about here.]

\subsubsection{Boreal}

[Figure 4 about here.]

The sites in the Boreal region are characterised by cold climates, with snow during the winter, and precipitation during summer. The main PFT is needleleaved evergreen trees, which results in fuel distributions with similar contributions to the 1-hr, 10-hr and 100-hr fuel classes. In combination with the low temperatures, the fuel loads result in the FDI rising slowly after a rain event (see Fig. 4), with fuel moisture being high unless a large dry spell takes place. The Canada site is unpopulated, the other sites do however have significant population densities. This means that in the Canada site, the only ignition sources will be lightning strikes.

\subsubsection{Savannas}

[Figure 5 about here.]

The savanna sites have clear dry/wet season dynamics, with high temperatures. The main PFTs are grasses, resulting in little or no fuel loads in the 10-hr or 100-hr classes. As fuel accumulation is controlled by precipitation during the rainy season, inter-annual fuel availability is typically dependent on precipitation. Additionally, since fires are frequent, there is not much chance of multi-annual litter accumulation, so that fuel loads are in general low for all the sites considered [REFERENCE]. The FDI is practically unity throughout the dry season (Fig. 5), resulting in no impediment to fires taking place during this period.

\subsubsection{Temperate}

[Figure 6 about here.] 
The temperate region sites are quite heterogenous, both in terms of vegetation and in terms of climate. While the California site is fairly indistinguishable from other savanna sites (for example, compare the FDI plots for California, Fig. 6(b), and Northern Australia, Fig. 5(d)), the Iberia site is characterised by having a few dry spells in the summer, and a heterogenous mixture of fuel types. The Argentina site is mainly covered in grasses,and has a number of rainfall events during the austral summer, but high temperatures result in fast drying out of fuels.

\subsubsection{Tropical}

[Figure 7 about here.]

The tropical region sites are typical rainforest sites in the Amazon and Borneo. They are characterised by high fuel loads, high relative humidity, high precipitation and high temperatures. In general, these sites are not fire-prone due to the continuous precipitation and high fuel moisture (Cochrane, 2003), as is obvious for the temporal plots of FDI shown in Fig. 7. There can, however, be years where drought conditions result in increased flammability, in particular in the Amazonas site, as there is a small proportion of grid cells with fairly high concentration of C4 grasses (up to $23 \%$ for some cells). This is not the case in Borneo, where all the gridcells are almost exclusively covered with tropical evergreen trees. We note that in (Thonicke et al., 2010), SPITFIRE substantially underestimates burned area for the tropical region.

\section{Results}

\subsection{Individual model components}

In the first instance, it is instructive to examine how parameters affect individual model components of the model, rather the whole model itself. In the case of SPITFIRE, we focus on the three main modules governing simulated area burnt: ignitions, fuel moisture dynamics and rate of spread.

\subsubsection{Potential ignitions}

Ignitions are modelled as the sum of lightning strikes ignitions and human ignitions. The former are derived by scaling an observed lightning flash climatology derived from satellite observations. A constant proportion of these flashes are assumed to be cloud-to-ground lightning strikes, and are thus a source of potential ignitions. Human ignitions sources, on the other hand, are modelled on the basis that as humans move into an area, fire is used to manage the land, clear forests, etc. After population grows, the combined effect of landscape fragmentation, extinction efforts, as well as the move towards less fire-intensive economic activities, results in a drop in the observed fire activity (Cochrane et al., 1999). In SPITFIRE, human ignitions are then a scaling of the population density, $P_{D}$, through a nonlinear function, that is then converted to potential human ignitions using an extra parameter:

$$
n_{h, i g}=P_{D} \cdot 30 . \exp \left[-0.5 \sqrt{P_{D}}\right] \cdot \frac{a_{N d}}{100}
$$


The exponential term in Eq. 13 has a peak for values of $P_{D}$ of $16 \mathrm{~km}^{-2}$.

In both lightning stike and human ignitions, the number of ignitions is directly proportional to the proportion of observed flashes that are deemed to be cloud-toground ones, and to the parameter that expresses the likelihood of humans igniting fires $\left(a_{N d}\right) . a_{N d}$ has units of ignitions per individual per fire season day (Thonicke et al., 2010). Clearly, these two parameters directly modulate the total number of potential ignitions, which in turn governs overall burned area.

\subsubsection{Fuel moisture dynamics}

In SPITFIRE, fuel moisture dynamics is governed by climate through the calculation of the Nesterov Index, fuel loads per fuel class and the moisture of extinction of different PFTs. The relative moisture content of all fuels is calculated from the NI, scaled by a weighted average of the contribution of each fuel type and a parameter that relates to the surface to area volume of the fuel class, as shown in Eq. 2. The rationale behind Eqns. 2 and 3 is to allow 1-hr fuels such as grasses, characterised by high SAV values to dry faster than low SAV 10-hr or 100-hr fuels (e.g., branches). In addition to this, if live grasses are present in the simulation unit, the 1-hr fuel class moisture content is modified by the livegrass moisture content. The latter is a function of top layer soil moisture (Thonicke et al., 2010).

The abundance of one or more types of fuels, coupled with the climatic history that defines the NI, are the major drivers of fuel moisture dynamics. In this respect, it is likely that different biomes will react very differently to factors controlling fuel moisture. For example, savannas tend to be characterised by a long dry season, with consistently high values of NI; the fuel load tends to be largely dominated grass, resulting in preponderance of dry $1 \mathrm{hr}$ fuels. In the boreal region, short dry spells and a mixture of the fuel types will make for a different impact of factors in fuel moisture. In the tropics, long dry seasons are needed to dry out the fuels. As such, any conclusion on the effect of model parameters on moisture dynamics will necessarily need to be biome and climate specific. Although in general, it can be said that parametrisations that result in fuels drying out faster will tend to increase burned area via increased $R o S$ (see Eq. 5).

\subsubsection{Rate of spread}

[Table 2 about here.]

[Table 3 about here.]

Rate of spread is calculated using Rothermel's equations (Rothermel, 1972; Pyne et al., 1996). In this Section, we carry out a sensitivity analysis on the different parameters that play a role in controlling rate of spread. We use the Sobol' method, and report the direct $S_{i}$ and total effects $S_{T i}$ in Table 2. While the direct effects of individual parameters are all negligible, the combined effects of the fuel bulk density, the fuel moisture content, the surface-to-area volume and wind speed all are very significant. 
It is interesting to consider a typical situation which appears often in savannas during the dry season. Firstly, we note that these sites are largely grassland sites (see Table 1). The FBD for these sites is then identical to that of $\mathrm{C} 3$ or $\mathrm{C} 4$ grasses, as there are no trees. During the dry season, the lack of rain events results in a long period where $F D I$ is unity. Even if rain events occur, the relatively high temperatures result in very localised drops in $F D I$, which are of little interest here. This is evident in the plots shown in Fig. 5). In this particular situation, $R o S$ is controlled by SAV and windspeed. Additionally, windspeed over the dry season for the savanna sites appears stationary in the NCEP dataset, so that ultimately, in these situations, SAV is the dominant factor controlling $R o S$. We have investigated this arguments by repeating the sensitivity analyses introduced in the previous paragraph, but only for values of fuel moisture content between 0 and 0.1 . The results in Table 3 show that this is the case, even considering that $\rho$ is given plenty of freedom to vary.

The two analyses presented in this Section suggest that rate of spread is largely controlled by FBD and SAV when fuels are dry. Wind speed is also important factor. A practical application of the SA work to a typical savanna environment shows that SAV controls rate of spread dynamics in typical dry season scenarios.

\subsection{Sensitivity analysis per biome}

[Table 4 about here.]

The parameters and parameter ranges used in the biome sensitivity analysis are presented in Table 4.

\subsubsection{Boreal forests}

[Figure 8 about here.]

The chosen sites, spread over the boreal regions of Eurasia and North America, show relatively large amounts of fuel, a consequence of the predominance of needle leafed evergreen trees. The contribution of trees to different fuel classes results in important share of fuels being in the 10 or 100 -hr classes, although due to litter accumulation, the $1 \mathrm{hr}$ fuel class also has an important role. In fact, it is the contribution of this latter class that enhances rate of spread through a lowering of the combined fuel bulk density and an increase of total surface area to volume ratios. Fuel bulk density is inversely proportional to rate of spread (Eq. 5). Surface area to volume ratios play an important role in the definition of the moisture content of fuels (higher values, associated with $1 \mathrm{hr}$ fuels, result in faster drying of fuels, and hence, in an enhancement of rate of spread).

In the Boreal region, dry spells need to be sufficiently long in order to dry fuels out, due to the low temperatures (see Fig. 4). If this dry period exists, and ignitions occur, then fires will spread as there is in general no shortage of fuel. The relevance of this observation is that the main controls on burned area for this area are related to fuel drying dynamics $\left(\alpha, \sigma_{1 h r}\right.$, etc.) and ignitions. We hypothesise that this will happen in sites that have a sufficiently long dry spell to allow for fuel drying, 
such as Canada, Siberia2 and (to a lesser extent) Alaska sites (see Figs.4(c), 4(d) and 4(a), respectively). Siberia (Fig. 4(b)), on the other hand, has abundant rain during the summer, resulting in consistenly low fire danger index values. Fuels will have very little chance of drying under these conditions. For the Siberia site, we expect that only factors affecting ignitions and fire duration, as they are a direct multipliear of burned area.

The results from the sensitivity analysis (see Fig. 8) consistently show the important interplay of factors directly controlling the simulated daily mean fire size (such as $\tau$ ) and fuel moisture ( $\alpha$, the moisture of extinction values, and the SAV). The number of ignitions plays no role in the largely unpopulated Canadian site, but it does play a role in the other sites, although the relatively low population density relegates the contribution of human ignitions to a second-order effect.

To control fire in the higher latitudes, the parameters need to enhance the periods conducent to fires, either by lowering the moisture of extinction or by drying out the fine fuels. Additionally, making fires last longer is another direct impact in the daily mean burned area that is directly transferred to the annual burned area.

In terms of repeatability of the results, the Canada and Siberia sites have relatively high values of $T D C C$, whereas the Alaska and Siberia2 sites have lower values. Interannual variability of climate in the Siberia2 site is important in the examined period, whereas both gridcell heterogeneity and internanual variability are important in the Alaska site. The other two sites are more homogenous in terms of vegetation and population dynamics, and have a more stable climatology during the study period, resulting in more coherent factor rank orderings. Note that all the higher ranking factors show an important contribution of higher order effects, suggesting an interplay of factors, evident in particular when several factors that control fuel moisture combine to make the fuels more or less moist.

\subsubsection{Savannahs}

[Figure 9 about here.]

Savannahs are fire prone biomes (Van Wilgen and Scholes, 1997). Climate on the chosen sites is characterised by a relatively large dry season that coupled with fairly high temperatures results in a long spell of very dry fuels (see Fig. 5, where the dry season is consistently obvious). During this period, it is the availability of fuel (limited either by wet season precipitation, directly related to fuel accumulation across these biomes or fire history (Van Wilgen and Scholes, 1997; Archibald et al., 2009)) and sources of ignition that control fire spread. The fact that the dry season is long means that vegetation will have a chance to dry out. Typically, grasses dry out quickly, so over the dry season, the only inhibiting factors affecting fires are ignitions, fuel and maximum fire duration, $\tau$ : as the fire danger index remains high during most of the dry season, and there is a dominance of grassy PFTs, the only effects on rate of spread arise from factors associated to grassy PFTs $\left(\sigma_{1 h r}\right.$, for example) and from changes in wind speed and reduction of the available fuel. Apart from these two factors, $a_{N d}$ is the other parameter controlling the daily 
burned area, an important contribution in these areas, where human ignitions are the main source of ignitions and population density weighting is also important. Simulations (see Fig. 9) confirm the previous points, with Cerrado, Miombo, Sahel and Mopane showing the importance of $\sigma_{1 h r}, \tau$ and $a_{N d}$, with different rank ordering of the parameters. In general, the very high $T D C C$ values suggest that the sites are homogeneous, and with relatively little inter-annual variation. The Northern Australian savannas, on the other hand, show an important contribution from soil moisture through its conversion into live fuel grass moisture content through factor $\kappa_{\omega}$. While this factor appears on other sites with a low impact, its importance on the Northern Australia site is striking. In this site, the phenology of C4 grasses derived from the MODIS time series has a slow transition from its peak around March, to its trough around September. This slow decline results in a significant contribution of live grass to the $1 \mathrm{hr}$ fuels up to September. Therefore, parameters controlling the moisture content of these live grasses, such as $\kappa_{\omega}$ will have a bearing on the fuel moisture.

In general, the results are quite stable for all regions, with Northern Australia showing the lowest values of $T D C C$, suggesting a more heterogeneous site.

\subsubsection{Temperate regions}

[Figure 10 about here.]

The sites that belong to the temperate region have a mixture of trees and grasses. Deciduous trees are quite common, which results in them having an important contribution to the 1-hr fuels pool through litter accumulation. In these ecosystems, fuel accumulation can happen over a large number of years due to relative infrequent fire activity. A typically dry summer is usually long enough to dry fuels, with ignitions being the major controlling factor in fires. This suggests that in temperate regions, $a_{N d}$ will have a great importance, together with parameters that control the drying out of fuels, eg $\alpha$ or $\sigma_{1 h r}$. Given the conditions conducent to dry fuels, it is again the duration of the fire, controlled through $\tau$, the factor that will have a very important effect on total burned area.

The results (Fig. 10) for Argentina and California are very similar, with $a_{N d}$, $\tau$ and $\sigma_{1 h r}$ all being prominent. This is similar to the savanna sites introduced in Section 2.4.2, and unsurprising, given that these temperate sites are very similar to the savanna sites (dominant vegetation is grasses, there is a long dry spell, with moderate to high temperatures).

The case of Iberia is more interesting. This region has significant precipitation during the summer, and moderate temperatures. The factors that control fuel moisture dynamics are thus of great importance, together with ignition sources. The lower values of $T D C C$ for this region can be abscribed to the higher interannual meteorological variability controlling fuel moisture.

\subsubsection{Tropical rainforest}

[Figure 11 about here.] 
Results for the tropical sites are different. In the Borneo site, the combination of drivers results in SPITFIRE being unable to simulate fires, unless the moisture of extinction is low enough to permit fires in typical moist conditions found in rainforests, with very short lived peaks of FDI (see Fig. 7(a)). In the Amazonas site (Fig. 11(a)), there is scope for fire, with the main factors affecting the simulated annual burned area being those relating to human-caused ignitions, maximum fire length $\tau$. The contribution of the 100-hr fuel class SAV, $\sigma_{100 h r}$, and the small effect of $\alpha$, as well as the FBD for the tropical evergreen trees suggest that in this site, rate of spread dynamics also have a direct impact on burned area.

\section{Discussion}

A schematic representation of SPITFIRE's calculation of daily burned area is a useful starting point to gain insights into the sensitivity analysis results presented in Section 2.2. Daily burned area is the combination of two terms: igntions and a mean fire size. The latter term is a function of rate of spread and fire duration. Ignitions are controlled mainly by a single parameter, $a_{N d}$, that maps population density into potential ignitions (lightning ignitions are based on lightning strike climatology). Rate of spread is a function of the characteristics of fuels present in the simulation unit, mainly fuel moisture (through a moisture dampening coefficient), fuel structure (through fuel bulk density and surface-to-area volume) and the amount of fuel present.

Moisture dynamics (calculated by a mapping of the Nesterov Index into a unitless moisture scalar) are also controlled by fuel structure through a weighting of the drying out rate of each fuel class, a parameter related to the ratio of surface-to-area volume of the different fuel classes. Through the Nesterov Index, fire danger is set to zero whenever a precipitation event of more than $3 \mathrm{~mm}$ takes place. However, the choice of $\alpha$ and SAVs controls how fast fuels will dry, and hence has an important knock-on effect on rate of spread calculations by controlling the moisture dampening coefficient $\eta$ and the heat of ignition, $Q_{i g}$. Broadly speaking, high values of SAV will result in faster drying rates.

In terms of rate of spread, it was shown in Section 3.1.3 that the main factors affecting its calculation are fuel bulk density, $\rho_{b}$ (a parameter specified per PFT) and SAV. Note that in that part of the study, there is no feedback of SAV through fuel moisture, as explained above. In general, $\rho_{b}$ is indirectly proportional to rate of spread (although it also plays a role in wind enhancement rate of spread calculations), while increasing SAV broadly increases rate of spread.

The fire danger index also controls fire duration, by scaling the fraction of the maximum fire duration parameter, $\tau$. This has a direct impact on daily burned area, particularly in situations where the fire danger index is high.

The preceding observations suggest that only a handful of factors are likely to play a role in modelling burned area. The way these factors affect the model output will be different in different biomes, mostly due to precipitation dynamics. In sites with large dry spells and high temperatures (typical of savannas and Mediterranean 
climates), the fire danger index will be unity for most of the dry season (see for example, Figs. 5(c) or 5(d)), and all fires will last the maximum fire duration. Other important factors will be those governing rate of spread (the other component of the mean fire size, and in this case, representative factors are $\sigma_{1 h r}$ and $\rho_{b}$ ), as well as the number of ignitions. However, these parameters will have a limited scope: if large, long fires burn all the available fuel in a few days at the beginning of the dry season, increasing potential ignitions will have no effect on total burned area. In this respect, these parameters have a "buffering" effect by limiting the combustion of biomass through less ignitions or slower rate of spread. If intermittent rains occur within the dry season (such as in the Sahel or Mopane sites, Figs. 5(a) and 5(b)), parameters controlling fuel drying will have an important impact, controlling the fire danger index during the dry spells between rain events, and hence rate of spread and fire duration.

In the boreal region, low temperatures result in a slower increase of the Nesterov Index which in turn requires longer dry spells to obtain a fire danger index nearing unity. This results in these areas having only short spikes of high fire danger index (e.g. Fig. 4(c)), as these sites experience continental climate regime, with rain precipitations mainly occurring during the summer period. In addition to that, the boreal region sites in the taiga region have large amounts of available fuels, with different fuel classes well-mixed. The combination of short periods conducent to fire and sufficient available fuel suggests that drying of fuels is a major controlling factor controlling burned area in the boreal region. Typically, rates of spread in these regions are moderated by the fuel loads and moisture content of the fuels. This limits the daily mean fire area calculations, in the same way that low fire danger indices result in short-lived fires (or in other words, the maximum fire duration is rarely realised, resulting in little impact of this parameter), an issue already pointed out in (Thonicke et al., 2010). Ignitions, on the other hand, directly increase on the daily burned area, and will have a strong effect, but only on those sites where population density is important (for example, the Canadian site is unpopulated, hence there can be no modelled human ignitions). The results presented in Section 2.2 confirm these arguments.

The temperate region sites are quite heterogeneous. In this case, the main climate type is not consistent, in particular in terms of precipitation partitioning in the summer. While the California site could arguably be labelled as a savanna site (compare, for example, the fire danger index plots for Northern Australia in Fig. 5(d) with those of California in Fig. 6(b)), Iberia shows significant precipitation in the summer (although with fairly large dry spells that allow for fuel drying), with moderate temperatures, not allowing the fire danger index to increase to unity. This suggests that parameters that control fuel drying will play an important role in temperate sites like Iberia or Argentina. In combination with a high fire danger index during the dry spells, the fire duration is another parameter that can have a strong effect. This explains the difference between Iberia and Argentina: in the former, $\tau$ is only important if the fuel moisture is low, hence the high score of $\sigma_{1 h r}$. 
In Argentina, the relatively high temperatures and predominance of fast drying fuels result in periods of very high FDI, so that $\tau$ will have an important effect. In Argentina, there is significant precipitation during the summer, allowing for a number of short dry spells with fire danger index values close to unity. The analysis of the California site results is very similar to that of the Sahel site: both sites show a similar vegetation and climate, and consequently, the results are comparable.

SPITFIRE has difficulties producing fires in the rainforest sites. This is due to the abundance of important rainfall events that results in low values of FDI. A way to produce fires is by lowering the moisture of extinction of the present PFTs, as fuel moisture is always fairly high due to the continuous rainfall. We observe that as soon as heterogeneity in PFT distribution is introduced (as is the case in some grid cells in the Amazonas site that have a significant proportion of grasses), other factors start playing a role.

\section{Conclusions}

While the rank order of their importance differs between different biomes, this study has demonstrated that the following parameters are key influences on simulated burnt area: ****LIST***.

In regions in which ignition sources exist and fuel is abundant but temperatures are either too low (boreal) or rainfall is too high (tropics), then parameters affecting drying rates of fuels are most important. In regions in which ignition sources exist and dry fuels exist but fuel buildup is highly variable (tropical savannas and mediterranean biomes), then parameters associated with the amount of fuel are most important. Temperate biomes are mixture of both

Then you need to tie this back into the introduction eg Flannigan paper decribing what limits fires in boreal zone etc. Lastly I would conclude along the lines of....

This study has important implications for the use of SPITFIRE as a model to predict future fire activity as part of a coupled land-vegetation-atmosphere system eg QESM (refs). SPITFIRE is demonstrably sensitive to small changes in values of a small set of parameters affecting sim burnt area. The challenge will be to work out how to provide better constrained measurements of these parameters using existing and future EO technologies and field experiments, and then to map these values at scales relevant to future GCM and earth system modelling.

\section{Acknowledgements}

Guido van der Werf is gratefully acknoweledged for providing the both the CASA/GFED code and the GFED 3.1 burned area dataset. The NCEP Reanalysis data were provided by the NOAA/OAR/ESRL PSD, Boulder, Colorado, USA, from their Web site at <http://www.esrl.noaa.gov/psd/>.

\section{References}

Andreae, M. O., Merlet, P., 2001. Emission of trace gases and aerosols from biomass burning. Global Biogeochemical Cycles 15 (4), 955-966. 
Archer, G., Saltelli, A., Sobol, I., 1997. Sensitivity measures, ANOVA-like techniques and the use of bootstrap. Journal of Statistical Computation and Simulation 58 (2), 99-120.

Archibald, S., Roy, D., Van Wilgen, B., Scholes, R., 2009. What limits fire?: An examination of drivers of burnt area in sub-equatorial Africa. Glob. Chang. Biol $15,613-630$.

Arora, V., Boer, G., 2005. Fire as an interactive component of dynamic vegetation models. Journal of Geophysical Research 110 (G2), G02008.

Bergeron, Y., Gauthier, S., Flannigan, M., Kafka, V., 2004. Fire regimes at the transition between mixedwood and coniferous boreal forest in northwestern Quebec. Ecology 85 (7), 1916-1932.

Byram, G., Davis, K., 1959. Forest fire: control and use. New York, Editions KP Davis.

Campolongo, F., Cariboni, J., Saltelli, A., 2007. An effective screening design for sensitivity analysis of large models. Environmental modelling \& software 22 (10), 1509-1518.

Campolongo, F., Saltelli, A., 1997. Sensitivity analysis of an environmental model: an application of different analysis methods. Reliability Engineering \& System Safety 57 (1), 49-69.

Canadian Forestry Service, 1992. Development and structure of the Canadian forest fire behaviour prediction system. Tech. Rep. ST-X-3, Forestry Canada Fire Danger Group, Ottawa, Ontario, Canada.

Cochrane, M., Alencar, A., Schulze, M., Souza Jr, C., Nepstad, D., Lefebvre, P., Davidson, E., 1999. Positive feedbacks in the fire dynamic of closed canopy tropical forests. Science 284 (5421), 1832.

Cochrane, M. A., 2003. Fire science for rainforests. Nature 421 (6926), 913-919.

Confalonieri, R., Bellocchi, G., Bregaglio, S., Donatelli, M., Acutis, M., 2010. Comparison of sensitivity analysis techniques: A case study with the rice model WARM. Ecological Modelling.

Confalonieri, R., Bellocchi, G., Tarantola, S., Acutis, M., Donatelli, M., Genovese, G., 2009. Sensitivity analysis of the rice model WARM in Europe: Exploring the effects of different locations, climates and methods of analysis on model sensitivity to crop parameters. Environmental Modelling \& Software.

Flannigan, M., Logan, K., Amiro, B., Skinner, W., Stocks, B., 2005. Future area burned in Canada. Climatic change 72 (1), 1-16. 
Giglio, L., Randerson, J. T., van der Werf, G. R., Kasibhatla, P. S., Collatz, G. J., Morton, D. C., DeFries, R. S., 2010. Assessing variability and long-term trends in burned area by merging multiple satellite fire products. Biogeosciences 7 (3), 1171-1186. URL http://www.biogeosciences.net/7/1171/2010/

Giglio, L., Van Der Werf, G. R., Randerson, J. T., Collatz, G. J., Kasibhatla, P., 2005. Global estimation of burned area using MODIS active fire observations. Atmospheric Chemistry and Physics Discussions 5 (6), 11091-11141.

Goldammer, J. G., Furyaev, V. V., 1996. Fire in ecosystems of boreal Eurasia: ecological impacts and links to the global system. Fire in ecosystems of Boreal Eurasia 48, 1-20.

Goldewijk, K. K., 2005. Three centuries of global population growth: A spatial referenced population (density) database for 1700-2000. Population and Environment 26, 343-367, 10.1007/s11111-005-3346-7.

URL http://dx.doi.org/10.1007/s11111-005-3346-7

Harris, S., Tapper, N., Packham, D., Orlove, B., Nicholls, N., 2008. The relationship between the monsoonal summer rain and dry-season fire activity of northern Australia. International Journal of Wildland Fire 17 (5), 674-684.

Helton, J., Johnson, J., Sallaberry, C., Storlie, C., 2006. Survey of sampling-based methods for uncertainty and sensitivity analysis. Reliability Engineering \& System Safety 91 (10-11), 1175-1209.

Kalnay, E., Kanamitsu, M., Kistler, R., Collins, W., Deaven, D., Gandin, L., Iredell, M., Saha, S., White, G., Woollen, J., et al., 1996. The NCEP/NCAR 40-year reanalysis project. Bulletin of the American Meteorological Society 77 (3), 437471.

Kitzberger, T., Swetnam, T., Veblen, T., 2001. Inter-hemispheric synchrony of forest fires and the El Niño-Southern Oscillation. Global Ecology and Biogeography 10 (3), 315-326.

Lehsten, V., Tansey, K., Balzter, H., Thonicke, K., Spessa, A., Weber, U., Smith, B., Arneth, A., 2008. Estimating carbon emissions from African wildfires. Biogeosciences Discussions 5 (4), 3091-3122.

Lenihan, J., Daly, C., Bachelet, D., Neilson, R., 1998. Simulating broad-scale fire severity in a dynamic global vegetation model. Northwest Science 72 (4), 91-101.

Morris, M., 1991. Factorial sampling plans for preliminary computational experiments. Technometrics 33 (2), 161-174.

Peterson, D., Ryan, K., 1986. Modeling postfire conifer mortality for long-range planning. Environmental Management 10 (6), 797-808. 
Potter, C., Randerson, J., Field, C., Matson, P., Vitousek, P., Mooney, H., Klooster, S., 1993. Terrestrial ecosystem production: a process model based on global satellite and surface data. Global Biogeochemical Cycles 7 (4), 811-841.

Pyne, S., Andrews, P., Laven, R., 1996. Introduction to wildland fire. John Wiley \& Sons Inc.

Randerson, J. T., Van der Werf, G. R., Collatz, G. J., Giglio, L., Still, C. J., Kasibhatla, P., Miller, J. B., White, J. W. C., DeFries, R. S., Kasischke, E. S., 2005. Fire emissions from $\mathrm{C} 3$ and $\mathrm{C} 4$ vegetation and their influence on interannual variability of atmospheric CO2 and d13CO2. Global Biogeochem. Cycles 19.

Rothermel, R., 1972. A mathematical model for predicting fire spread in wildland fuels. Tech. Rep. INT-115, Forest Service, US Department of Agriculture, Ogden, UT.

Saltelli, A., 2002. Making best use of model evaluations to compute sensitivity indices. Computer Physics Communications 145 (2), 280-297.

Saltelli, A., Chan, K., Scott, E., et al., 2004. Sensitivity analysis. Wiley New York.

Thonicke, K., Spessa, A., Prentice, I. C., Harrison, S. P., Dong, L., CarmonaMoreno, C., 2010. The influence of vegetation, fire spread and fire behaviour on biomass burning and trace gas emissions: results from a process-based model. Biogeosciences 7 (6), 1991-2011.

URL http://www.biogeosciences.net/7/1991/2010/

Thonicke, K., Venevsky, S., Sitch, S., Cramer, W., 2001. The role of fire disturbance for global vegetation dynamics: coupling fire into a Dynamic Global Vegetation Model. Global Ecology and Biogeography 10 (6), 661-677.

Thorsen, S., Roer, A., van Oijen, M., 2010. Modelling the dynamics of snow cover, soil frost and surface ice in Norwegian grasslands. Polar Research 29 (1), 110-126.

van der Werf, G., Randerson, J., Collatz, G., Giglio, L., Kasibhatla, P., Arellano Jr, A., Olsen, S., Kasischke, E., 2004. Continental-scale partitioning of fire emissions during the 1997 to $2001 \mathrm{El} \mathrm{Nino/La} \mathrm{Nina} \mathrm{period.} \mathrm{Science} 303$ (5654), 73.

van der Werf, G., Randerson, J., Giglio, L., Collatz, G., Mu, M., Kasibhatla, P., Morton, D., DeFries, R., Jin, Y., van Leeuwen, T., 2010. Global fire emissions and the contribution of deforestation, savanna, forest, agricultural, and peat fires (1997-2009). Atmos. Chem. Phys. Discuss 10, 16153-16230.

van der Werf, G., Randerson, J., Giglio, L., Gobron, N., Dolman, A., 2008. Climate controls on the variability of fires in the tropics and subtropics. Global Biogeochemical Cycles 22 (3).

Van der Werf, G. R., Randerson, J., Collatz, G., Giglio, L., 2003. Carbon emissions from fires in tropical and subtropical ecosystems. Global Change Biology 9 (4), $547-562$. 
Van der Werf, G. R., Randerson, J. T., Giglio, L., Collatz, G. J., Kasibhatla, P. S., Arellano Jr, A. F., 2006. Interannual variability of global biomass burning emissions from 1997 to 2004. Atmospheric Chemistry and Physics Discussions $6(2), 3175-3226$.

Van Wilgen, B., Scholes, R., 1997. The vegetation and fire regimes of southern hemisphere Africa. In: Andreae, M. O., Goldammer, J. G., Lindsay, K. (Eds.), Fire in southern African savannas. Witwatersand University Press, pp. 27-46.

Venevsky, S., Thonicke, K., Sitch, S., Cramer, W., 2002. Simulating fire regimes in human-dominated ecosystems: Iberian Peninsula case study. Global Change Biology 8 (10), 984-998.

Whelan, R. J., 1995. The ecology of fire. Cambridge Univ Press. 


\section{List of Figures}

1 A diagram showing the main processes that influence the calculation of daily burned area in SPITFIRE. . . . . . . . . . . . . . 24

A cartoon example of typical output from the Morris methodology.

This fictitious example has five factors, $A, B, C, D$ and $E$. . . . 25

Spatial distribution of test sites . . . . . . . . . . . 26

Fire Danger index. Boreal region sites . . . . . . . . . . . . 27

Fire Danger Index. Savannah sites . . . . . . . . . . . . . . 28

Fire Danger Index. Temperate region sites . . . . . . . . . . . . . 29

Fire Danger Index. Tropical region sites . . . . . . . . . . . . . 30

Results of sensitivity analysis. Boreal region sites . . . . . . . . . 31

9 Results of sensitivity analysis. Savannah sites . . . . . . . . . . . 32

10 Results of sensitivity analysis. Temperate region sites . . . . . . . 33

11 Sensitivity analysis of the (a) Amazonas and (b) Borneo sites. . . . . 34 


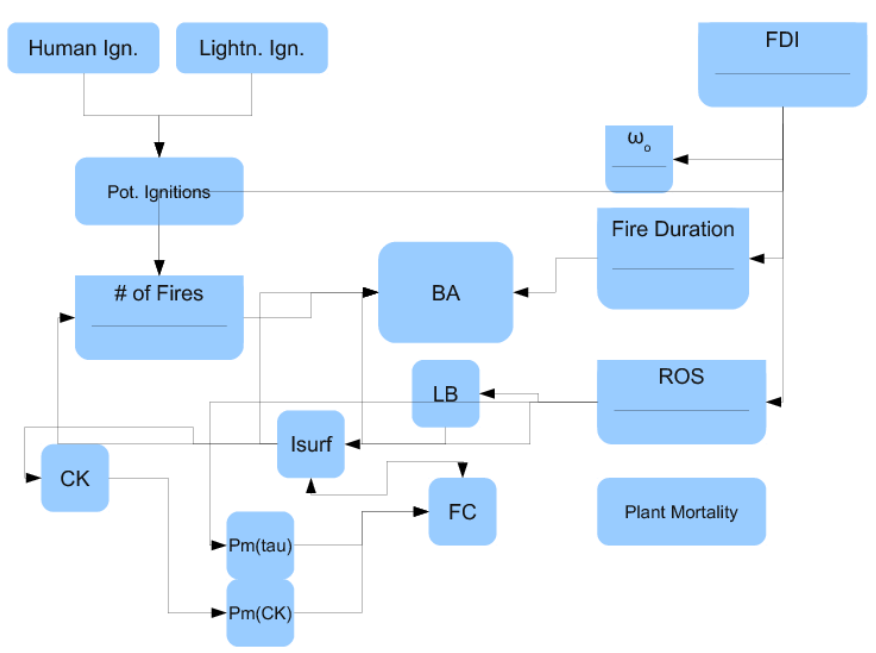

Figure 1: A diagram showing the main processes that influence the calculation of daily burned area in SPITFIRE. 


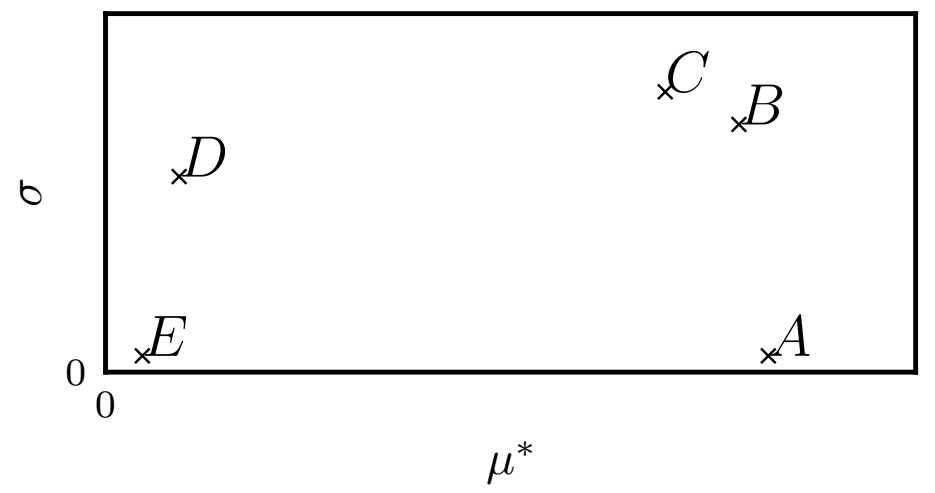

Figure 2: A cartoon example of typical output from the Morris methodology. This fictitious example has five factors, $A, B, C, D$ and $E$. 

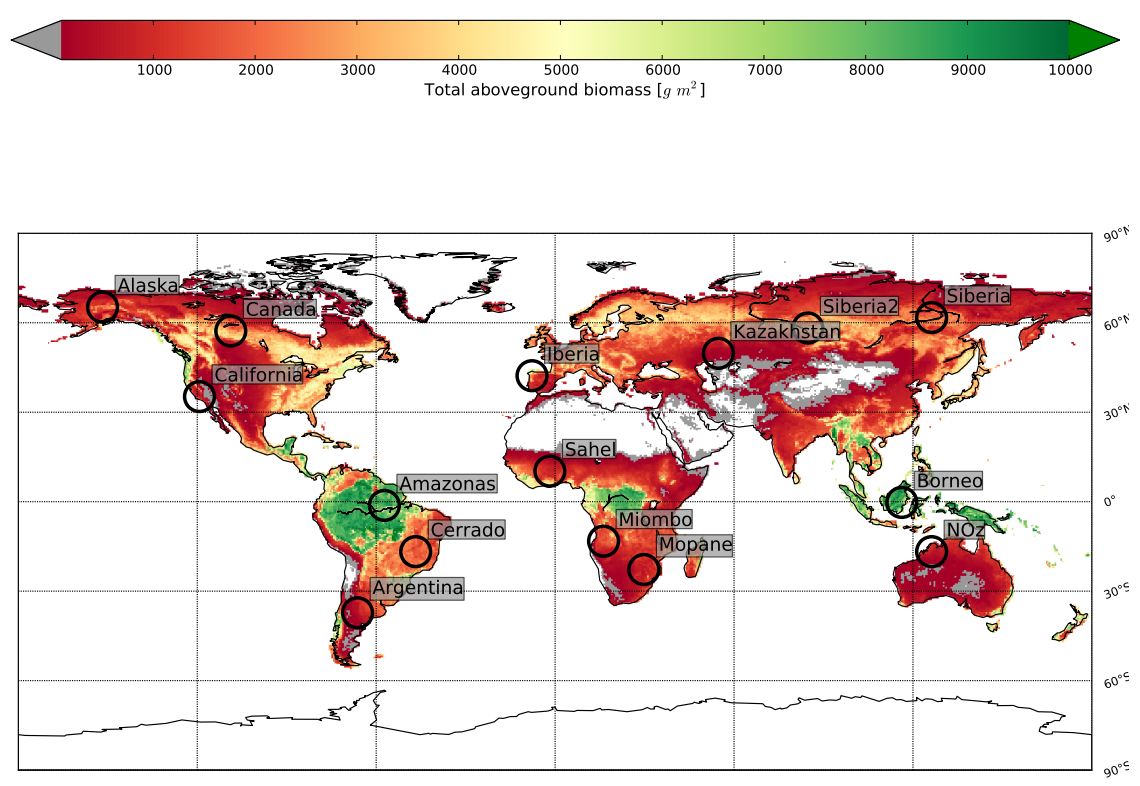

Figure 3: Spatial distribution of test sites 


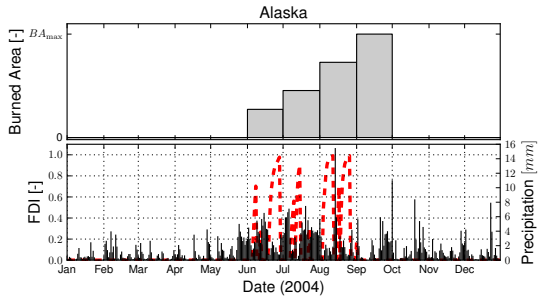

(a) Alaska

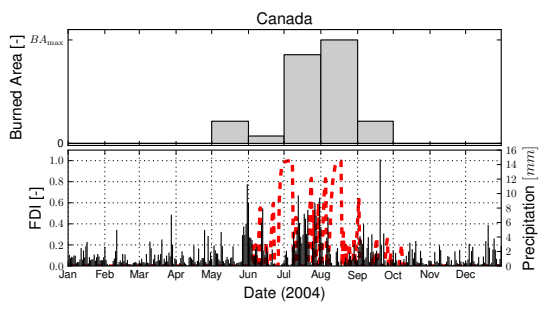

(c) Canada

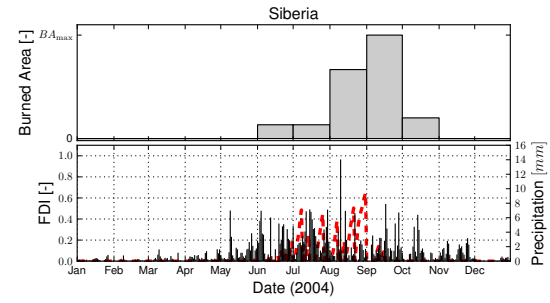

(b) Siberia

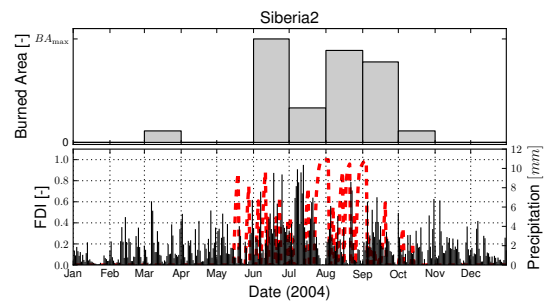

(d) Siberia 2

Figure 4: Distribution of monthly burned area according to GFED3 (Giglio et al., 2010) (top panels), and temporal evolution of the fire danger index (FDI) for the boreal region sites in 2004: (a) Alaska, (b) Siberia, (c) Canada and (d) Siberia2. 


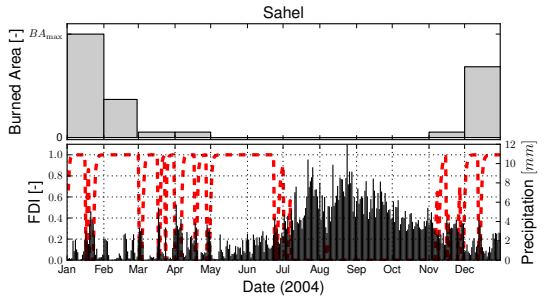

(a) Sahel

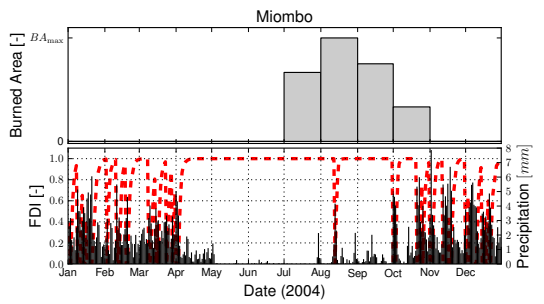

(c) Miombo

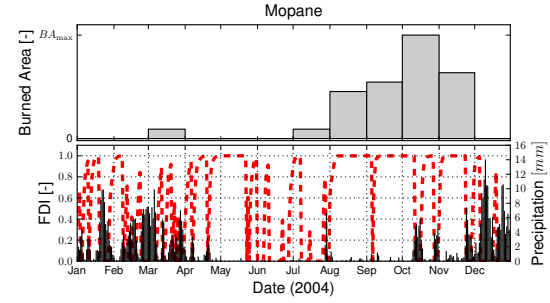

(b) Mopane

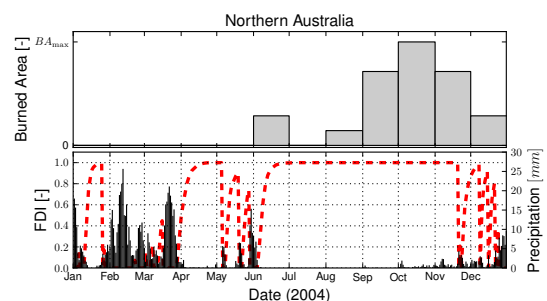

(d) Northern Australia

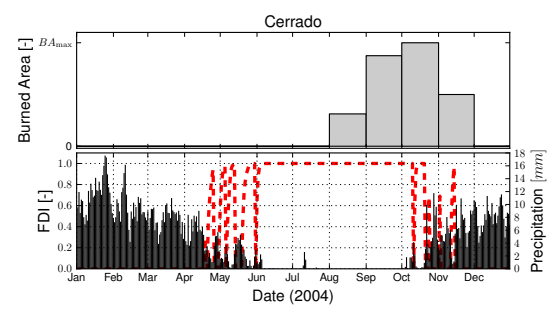

(e) Cerrado

Figure 5: Distribution of monthly burned area according to GFED3 (Giglio et al., 2010) (top panels), and temporal evolution of the fire danger index (FDI) for the savanna sites in 2004: (a) Sahel, (b) Mopane, (c) Miombo, (d) Northern Australia and (e) Cerrado. 


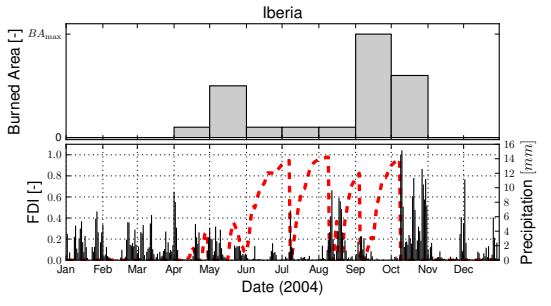

(a) Iberia

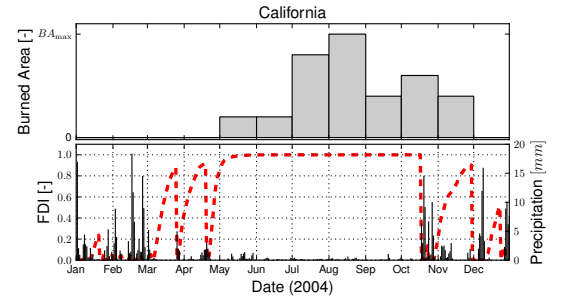

(b) California

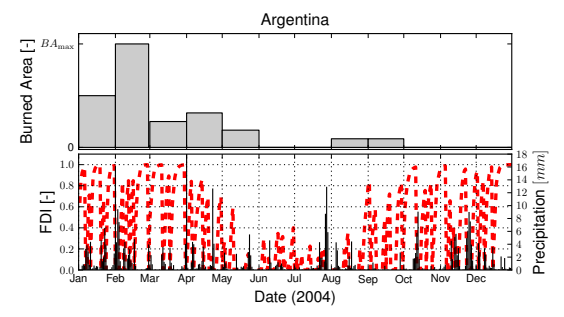

(c) Argentina

Figure 6: Distribution of monthly burned area according to GFED3 (Giglio et al., 2010) (top panels), and temporal evolution of the fire danger index (FDI) for the temperate region sites in 2004: (a) Iberia, (b) California and (c) Argentina. 


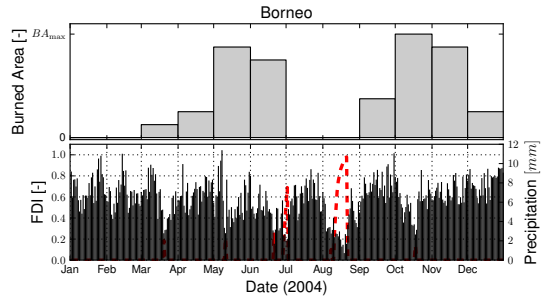

(a) Borneo

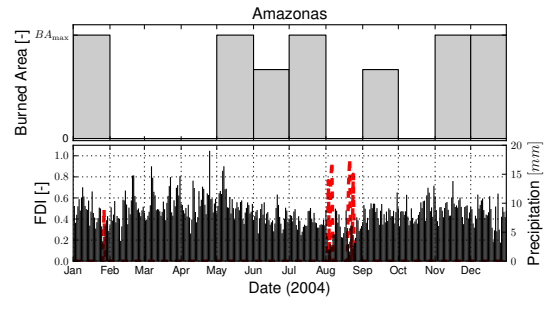

(b) Amazonas

Figure 7: Distribution of monthly burned area according to GFED3 (Giglio et al., 2010) (top panels), and temporal evolution of the fire danger index (FDI) for the tropical region sites in 2004: (a) Borneo and (b) Amazonas. 


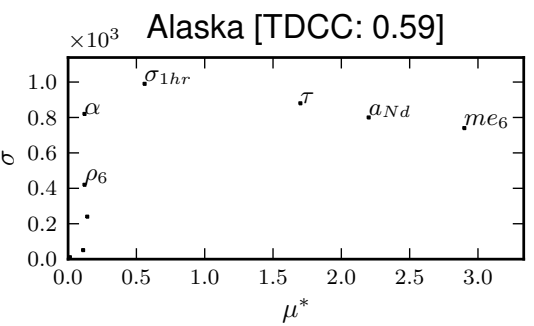

(a) Alaska

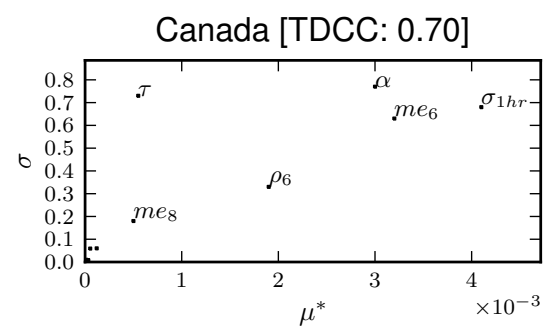

(c) Canada

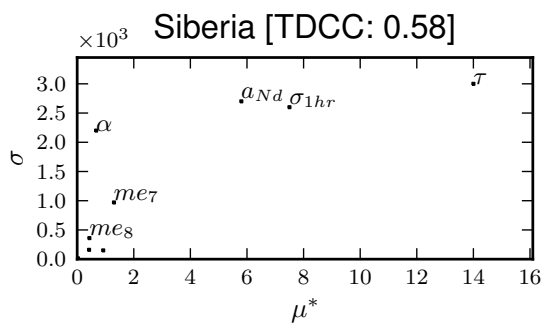

(b) Siberia

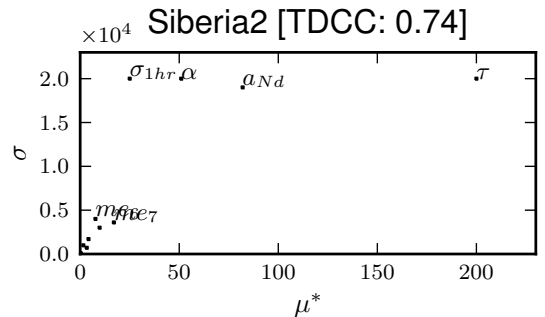

(d) Siberia 2

Figure 8: Sesitivity analysis results for the boreal region sites: (a) Alaska , (b) Siberia, (c) Canada and (d) Siberia2. 


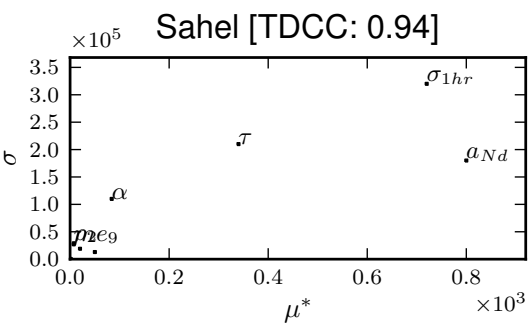

(a) Sahel

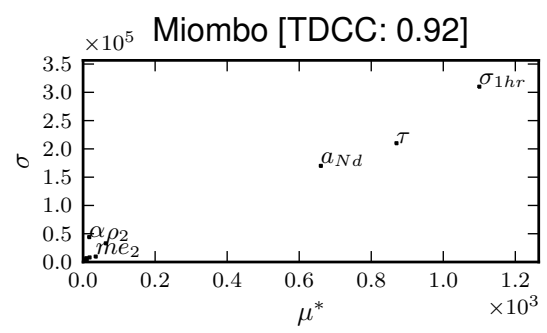

(c) Miombo

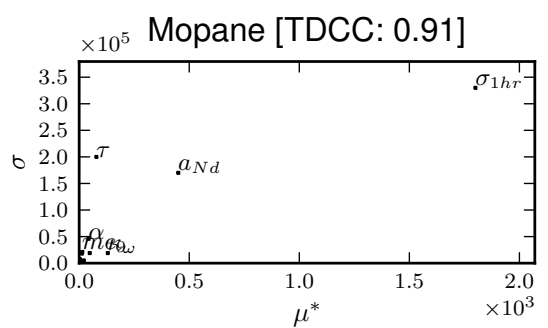

(b) Mopane

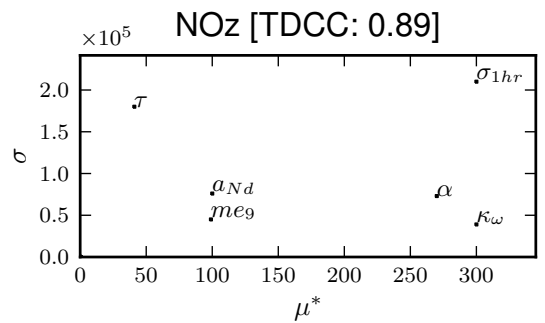

(d) Northern Australia

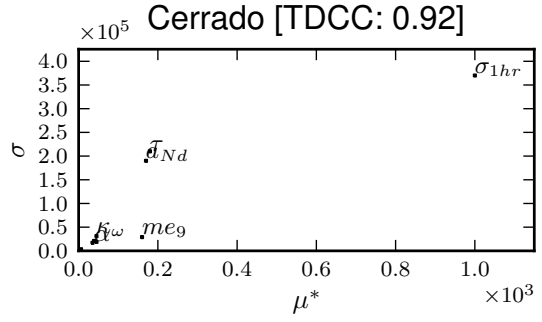

(e) Cerrado

Figure 9: Sesitivity analysis results for the savanna sites: (a) Sahel, (b) Mopane, (c) Miombo, (d) Northern Australia and (e) Cerrado. 


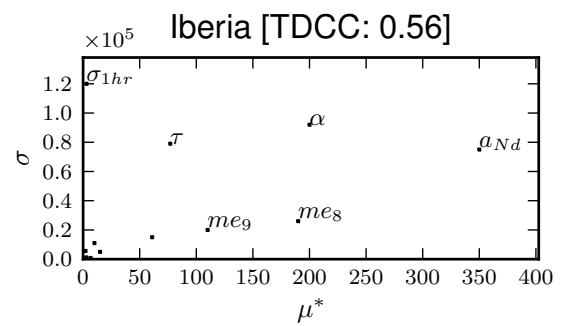

(a) Iberia

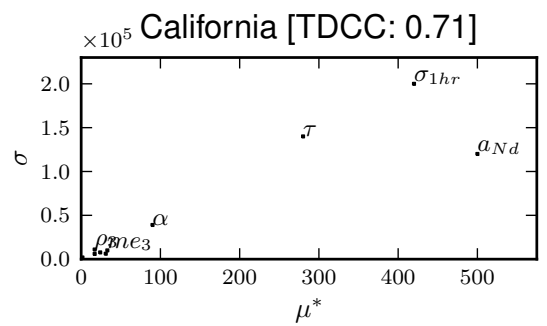

(b) California

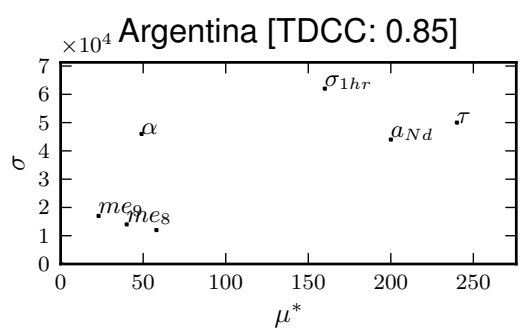

(c) Argentina

Figure 10: Sesitivity analysis results for the temperate region sites: (a) Iberia, (b) California and (c) Argentina. 


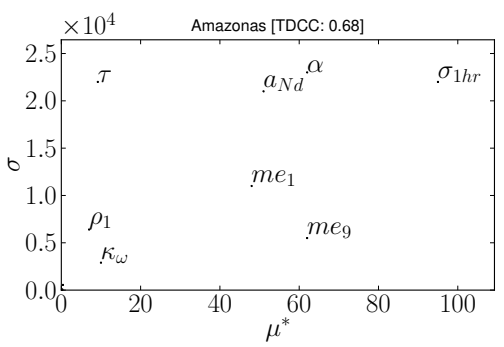

(a) Amazonas

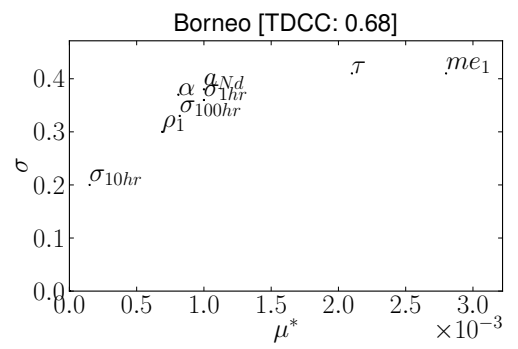

(b) Borneo

Figure 11: Sensitivity analysis of the (a) Amazonas and (b) Borneo sites. 


\section{List of Tables}

Description of sites . . . . . . . . . . . . . 36

2 Sensitivity analysis of Rate of Spread according to Rothermel's equa-

tions. . . . . . . . . . . . . . . . . 37

3 Sensitivity analysis of Rate of Spread according to Rothermel's equations for dry fuels. . . . . . . . . . . . . . . . . 38

4 Parameters included in the sensitivity analysis exercise, with the symbol used in the text, the range of values used, the default values used in (Thonicke et al., 2010) and the units. . . . . . . . . . . . . . 39 


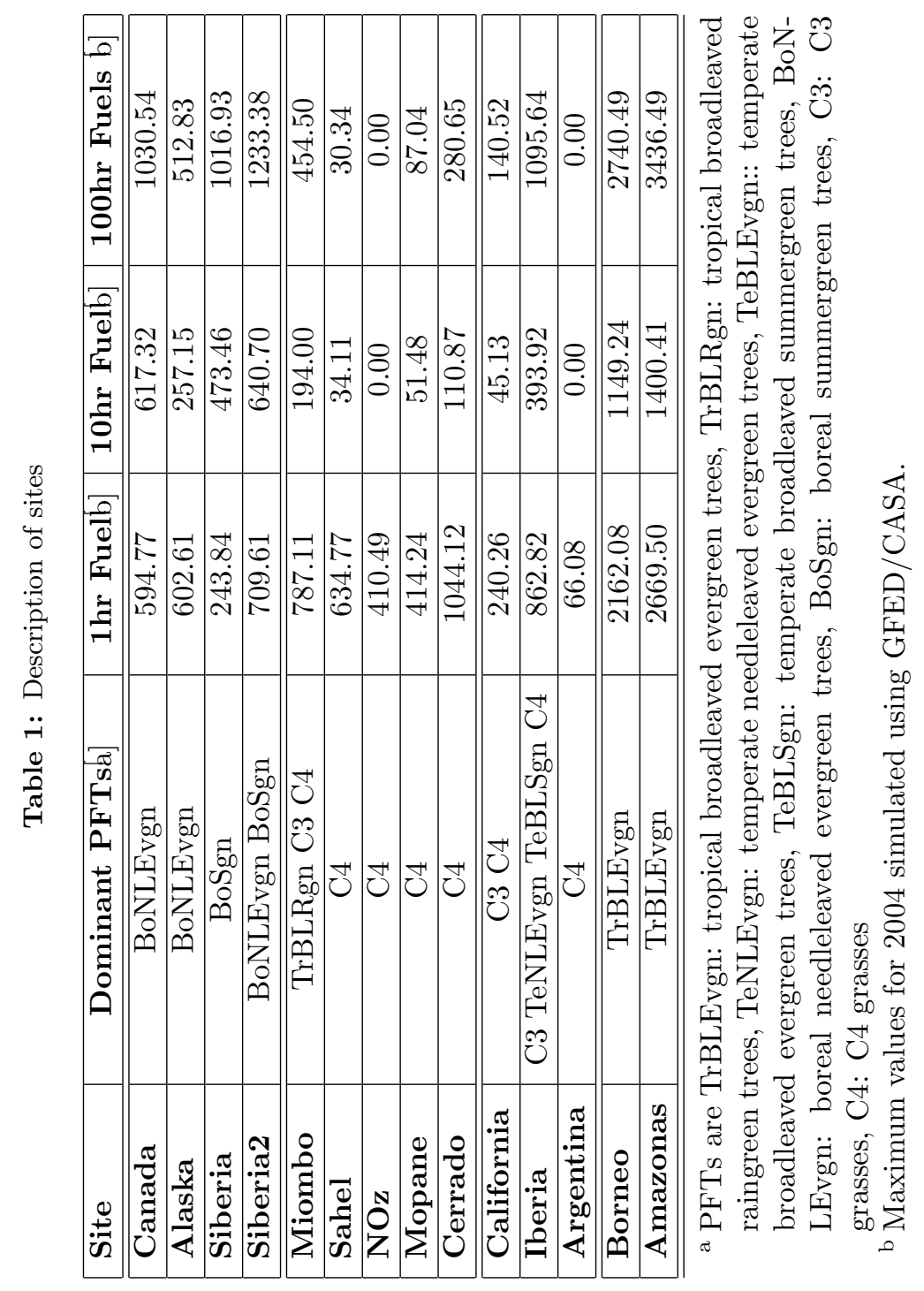




\begin{tabular}{|c|c|c|c|c|}
\hline Factor & Minimum value & Maximum value & $S_{i}$ & $S_{T i}$ \\
\hline \hline Fuel bulk density & 0.1 & 40 & 0.005 & 0.92 \\
\hline Surface-area volume & 0.1 & 200 & 0.001 & 0.59 \\
\hline Fuel moisture content & 0 & 1 & 0.01 & 0.95 \\
\hline Wind speed & 1 & 500 & 0.001 & 0.13 \\
\hline Particle Density & 410 & 614 & $\sim 0$ & 0.002 \\
\hline Heat content & 144000 & 21600 & $\sim 0$ & 0.026 \\
\hline Total mineral content & $0 \%$ & $10 \%$ & $\sim 0$ & 0.006 \\
\hline
\end{tabular}

Table 2: Sensitivity analysis of Rate of Spread according to Rothermel's equations. 


\begin{tabular}{|c|c|c|c|c|}
\hline Factor & Minimum value & Maximum value & $S_{i}$ & $S_{T i}$ \\
\hline \hline Fuel bulk density & 0.1 & 40 & 0.1 & 0.95 \\
\hline Surface-area volume & 0.1 & 200 & 0.1 & 0.48 \\
\hline Fuel moisture content & 0 & 0.1 & $\sim 0$ & 0.06 \\
\hline Wind speed & 1 & 500 & 0.001 & 0.46 \\
\hline Particle Density & 410 & 614 & $\sim 0$ & 0.003 \\
\hline Heat content & 144000 & 21600 & $\sim 0$ & 0.016 \\
\hline Total mineral content & $0 \%$ & $10 \%$ & $\sim 0$ & 0.01 \\
\hline
\end{tabular}

Table 3: Sensitivity analysis of Rate of Spread according to Rothermel's equations for dry fuels. 


\begin{tabular}{|c|c|c|c|c|c|}
\hline Parameter & Symbol & Min val. & Max. val. & Def. val. & Units \\
\hline \hline SAV 1hr fuels & $\sigma_{1 h r}$ & 5 & 300 & 66 & $\mathrm{~cm}^{-1}$ \\
SAV 10hr fuels & $\sigma_{10 h r}$ & 0.49 & 1.47 & 3.58 & $\mathrm{~cm}^{-1}$ \\
SAV 100hr fuels & $\sigma_{100 h r}$ & 1.8 & 5.4 & 0.98 & $\mathrm{~cm}^{-1}$ \\
Moisture constant 1hr & $\alpha_{1 h r}$ & $5 \mathrm{E}-4$ & $4 \mathrm{E}-3$ & $1 \mathrm{E}-3$ & ${ }^{\circ} \mathrm{C}^{2}$ \\
Moisture extinction 1 & $m_{e, 1}$ & 0.1 & 0.3 & 0.2 & - \\
Moisture extinction 2 & $m_{e, 2}$ & 0.1 & 0.5 & 0.3 & - \\
Moisture extinction 3 & $m_{e, 3}$ & 0.1 & 0.5 & 0.3 & - \\
Moisture extinction 4 & $m_{e, 4}$ & 0.1 & 0.5 & 0.3 & - \\
Moisture extinction 5 & $m_{e, 5}$ & 0.1 & 0.5 & 0.3 & - \\
Moisture extinction 6 & $m_{e, 6}$ & 0.1 & 0.5 & 0.35 & - \\
Moisture extinction 7 & $m_{e, 7}$ & 0.1 & 0.5 & 0.35 & - \\
Moisture extinction 8 & $m_{e, 8}$ & 0.1 & 0.5 & 0.2 & - \\
Moisture extinction 9 & $m_{e, 9}$ & 0.1 & 0.5 & 0.2 & - \\
Fire Duration factor & $\tau$ & 0.01 & 5 & 10.9 & - \\
Anthr. ign. factor & $a_{N d}$ & 0.05 & 15 & 0.3 & $\mathrm{UNITS}^{-3}$ \\
Fuel Bulk Density 1 & $\rho_{1}$ & 10 & 25 & 14 & $\mathrm{kgm}^{-3}$ \\
Fuel Bulk Density 2 & $\rho_{2}$ & 10 & 25 & 12 & $\mathrm{kgm}^{-3}$ \\
Fuel Bulk Density 3 & $\rho_{3}$ & 16 & 31 & 23 & $\mathrm{kgm}^{-3}$ \\
Fuel Bulk Density 4 & $\rho_{4}$ & 10 & 16 & 28 & $\mathrm{kgm}^{-3}$ \\
Fuel Bulk Density 5 & $\rho_{5}$ & 13 & 22 & 22 & $\mathrm{kgm}^{-3}$ \\
Fuel Bulk Density 6 & $\rho_{6}$ & 18 & 30 & 18 & $\mathrm{kgm}^{-3}$ \\
Fuel Bulk Density 7 & $\rho_{7}$ & 16 & 22 & 16 & $\mathrm{kgm}^{-3}$ \\
Fuel Bulk Density 8 & $\rho_{8}$ & 1 & 2 & 4 & $\mathrm{kgm}^{-3}$ \\
Fuel Bulk Density 9 & $\rho_{9}$ & 1 & 2 & 2 & $\mathrm{kgm}^{-3}$ \\
\hline
\end{tabular}

Table 4: Parameters included in the sensitivity analysis exercise, with the symbol used in the text, the range of values used, the default values used in (Thonicke et al., 2010) and the units. 